\title{
Revestimentos de fachadas de edifícios do século XIX em Salvador: reflexões sobre danos e suas causas.
}

\author{
A. Magalhães ${ }^{1 *}$, R. Muñoz ${ }^{2}$ \\ *Autor de Contato: anacristian01@gmail.com \\ ${ }^{1}$ Grupo de pesquisa CREPE, Faculdade de Arquitetura, Universidade Federal da Bahia, Salvador, Brasil \\ ${ }^{2}$ Grupo de pesquisa CREPE, Faculdade de Arquitetura, Universidade Federal da Bahia, Salvador, Brasil
}

\begin{abstract}
RESUMO
Os revestimentos desempenham relevante papel na durabilidade das alvenarias dos edifícios, já que asseguram proteção contra as ações agressivas de natureza física, mecânica, química, biológica e/ou antrópica. Este trabalho objetiva identificar as principais anomalias, formas de manifestação e suas possíveis causas, em fachadas de edifícios do século XIX em Salvador. De caráter qualitativo e exploratório, esta pesquisa seguiu método científico de abordagem empírica, a partir da realização de levantamento bibliográfico sobre o tema, seguido de análise críticocomparativa. A originalidade deste estudo se encerra na contemporaneidade da sua execução. Como resultado, obteve-se a sistematização dos danos e suas causas mais prováveis, o que contribui para a elaboração de diagnóstico detalhado e tomada de decisões em intervenções para preservação do patrimônio edificado.
\end{abstract}

Palavras-chave: revestimentos; danos; fachadas; patrimônio; Centro Histórico de Salvador.

\section{ABSTRACT}


Coatings play an important role in the durability of building masonry, as they ensure protection against aggressive physical, mechanical, chemical, biological and anthropic actions. This work aims to identify the main anomalies, forms of manifestation and their possible causes on the façades of 19th century buildings in Salvador. With a qualitative and exploratory character, this research followed a scientific method with an empirical approach, based on a bibliographical survey on the subject, followed by a critical-comparative analysis. The originality of this study ends in the contemporaneity of its execution. As a result, systematization of anomalies and their most probable causes was obtained, which contributes to the elaboration of a detailed diagnosis and decision-making in interventions for the preservation of the built heritage.

Key words: coatings; damage; facades; heritage; Historic Center of Salvador.

\section{RESUMEN}

Los revestimientos juegan un papel importante en la durabilidad de la mampostería de construcción, ya que garantizan la protección contra acciones físicas, mecánicas, químicas, biológicas y / o antrópicas agresivas. Este trabajo tiene como objetivo identificar las principales anomalías, formas de manifestación y sus posibles causas, en las fachadas de edificios del siglo XIX en Salvador. Con carácter cualitativo y exploratorio, esta investigación siguió un método científico con enfoque empírico, basado en la investigación bibliográfica sobre el tema, seguida de un análisis crítico-comparativo. La originalidad de este estudio desemboca en la contemporaneidad de su ejecución. Como resultado se obtuvo la sistematización de anomalías y sus causas más probables, lo que contribuye a la elaboración de un diagnóstico detallado y toma de decisiones en intervenciones para la preservación del patrimonio construido.

Palabras clave: revestimientos; daño; fachadas; patrimonio; Centro Historico de Salvador.

\section{INTRODUÇÃO}

No exterior das edificações tradicionais ${ }^{1}$, é comum observarem-se várias manifestações de anomalias, já que os materiais que revestem as fachadas, por estarem em contacto com o meio ambiente, ficam expostos à ação direta e continuada de diversos agentes de degradação. Estes revestimentos tradicionais de paredes, geralmente constituídos por argamassa de cal aérea, são caracterizados por uma estrutura de porosidade aberta com maior ou menor susceptibilidade às ações físicas, mecânicas, químicas, biológicas e antrópicas. Convém, portanto, que sejam realizados estudos para um melhor conhecimento das causas e das formas de manifestação dos danos, que constituem dados imprescindíveis para esclarecer a situação, visando a elaboração de um diagnóstico correto.

Para avaliação dos danos nos revestimentos de fachadas, é necessária a realização prévia da identificação e conhecimento do bem, etapa que compreende: análise visual (levantamento das anomalias para uma primeira verificação do estado de conservação do edifício) e registro fotográfico; pesquisa histórica, com destaque para a anotação de intervenções pelas quais o edifício foi submetido; levantamento planialtimétrico; análise tipológica (identificação dos materiais e sistemas construtivos); análise ambiental (avaliação de condicionantes extrínsecas ao objeto);

\footnotetext{
1 Este termo refere-se às construções executadas em terra ou alvenaria (tijolo, pedra ou mista), cuja tecnologia construtiva antecedeu ao advento do cimento Portland. De acordo com Veiga e Tavares (2002), no que tange às edificações antigas, as suas propriedades eram diferentes das atuais; normalmente construídas com materiais porosos e grandes espessuras, possuíam revestimentos adequados para garantir proteção e bom funcionamento das alvenarias, admitindo a entrada de água para o interior e, ao mesmo tempo, evitando a sua permanência prolongada.
} 
prospecções (arquitetônica, do sistema construtivo, arqueológica); ensaios (não destrutivos, semi destrutivos e complementares), além de análises computacionais (Brasil, 2005; Magalhães, 2013). Após essa etapa é realizado o diagnóstico, que compreende a "[...] consolidação dos estudos e pesquisas anteriormente realizados, na medida em que complementa o conhecimento do objeto, analisando de forma pormenorizada determinados problemas ou interesses específicos" (Brasil, 2005, p. 28). São suas partes constituintes: o mapeamento de danos, com causas e agentes, e a elaboração de relatório detalhado.

Neste sentido, o presente estudo tem como objetivo identificar as principais formas de manifestação de anomalias e suas possíveis causas, em fachadas de edifícios do século XIX, no Centro Histórico de Salvador (CHS), patrimônio único e precioso de valor histórico, artístico e cultural, considerado como um expressivo exemplar do urbanismo ultramarino português. O CHS contempla, basicamente, edificações dos séculos XVI ao XIX, caracterizadas por conjuntos monumentais da arquitetura religiosa, civil e militar. Além dos belíssimos sobrados, geralmente de três a cinco pavimentos, as marcas da ocupação e urbanização lusitana no período colonial estão presentes ainda nas ruas e calçadas estreitas, que remetem a cidades tradicionais portuguesas.

Devido à ação do tempo, às condições agressivas da região costeira, à ação humana e/ou à falta de manutenção, muitos edifícios, considerados como cartão postal, apresentam problemas de degradação, principalmente nos revestimentos de paredes.

O desconhecimento das principais anomalias, de suas formas de manifestação e das possíveis causas que atuam em sua origem, tem levado, por vezes, a diagnósticos incorretos e, portanto, à adoção de medidas inadequadas de intervenção e reparação. Nas obras atuais faz-se necessário conhecer e respeitar o funcionamento das paredes antigas, encontrando soluções compatíveis para evitar o desencadeamento de danos. Justifica-se, assim, a importância deste trabalho, principalmente no que tange à atualização, sistematização e interpretação de informações para fundamentar e definir de forma criteriosa estratégias de atuação que visem eliminar ou controlar causas dos danos nas edificações, visando a preservação do patrimônio edificado.

Para a obtenção do objetivo proposto, foi realizada, previamente, revisão bibliográfica sobre o estado da arte das anomalias mais comuns em revestimentos de fachadas de edificações antigas, seguida de levantamento de campo e estudo dos objetos selecionados a partir de critérios qualitativos, além de avaliação crítica dos resultados, embasada em inspeções realizadas no local e aporte científico.

\section{BREVE APORTE TEÓRICO SOBRE DANOS}

Os seguintes danos são mais frequentes em revestimentos de paredes de fachadas: manchas de umidade, descontinuidades (microfissuras, fissuras e trincas), perda de aderência (descolamento, abaulamento, destacamento), eflorescências e criptoflorescências, perda de coesão ou desagregação, biodeterioração ${ }^{2}$, erosão e sujidade (Villanueva, 1998; Magalhães, 2013).

No que tange à umidade, a água é o agente de deterioração que mais afeta as alvenarias e seus revestimentos, sendo a causa primária ou secundária de muitas anomalias. A sua ocorrência no interior da estrutura porosa pode resultar em problema, se o material estiver submetido a ciclos de molhagem/secagem. Além de afetar a durabilidade do revestimento, a presença de água acelera outros mecanismos de degradação, uma vez que é condição necessária à ação de outros agentes, tais como: os gases poluentes, os sais (quando dissolvidos na água, podem originar fenômenos de eflorescências), os microrganismos e organismos (cujo crescimento biológico requer a presença de água), entre outros.

\footnotetext{
${ }^{2}$ Neste texto, o termo biodeterioração compreende danos decorrentes da ação tanto de animais (microscópicos, insetos, aracnídeos, roedores, aves, mamíferos, entre outros), como de vegetais (musgos e plantas de porte) e outros: algas, cianobactérias, fungos (mofos) e liquens (Carrió, 2000; Souza, Pereira, Brito, 2005).
} 
Entende-se por umidade o aparecimento de teor de água superior ao desejado em um revestimento, seja na sua superfície (acabamento), seja na própria argamassa, manifestando-se sob a forma de manchas. As fontes mais comuns de umidade excessiva nos edifícios são: de obra ou de construção (água empregada para a execução e aplicação do revestimento); do terreno (em consequência da ascensão de água por capilaridade, através da estrutura porosa do material, devido à existência de locais em contato com a água do solo, à presença de materiais de elevada capilaridade nas paredes ou à inexistência, ou deficiente posicionamento, de barreiras estanques nas paredes); de precipitação (quando associada à atuação do vento pode dar origem ao aparecimento de manchas nos paramentos); de condensação (surge devido ao vapor de água gerado no interior dos edifícios); decorrente de fenômenos de higroscopicidade (surge quando os revestimentos contendo sais solúveis entram em contato com água sob a forma líquida ou de vapor, constituindo uma espécie de depósitos de água); devido a causas fortuitas, tais como ruptura de canalizações, entupimento de tubos de queda, coberturas danificadas, entre outros (Henriques, 2001; Magalhães, 2013).

As descontinuidades compreendem as microfissuras, fissuras e trincas. As primeiras são definidas como toda abertura longitudinal curta, fina e com desenvolvimento discreto, que afeta somente a parte superficial do revestimento. Considera-se trinca qualquer abertura longitudinal que atravessa toda a espessura do revestimento, chegando a rompê-lo, tornando possível distinguir bem as duas partes do elemento construtivo.

Não há definição unânime sobre essa nomenclatura, nem mesmo sobre a amplitude das descontinuidades. Os institutos brasileiros de avaliação e perícias de engenharia, IBAPE-MG (2014) e o IBAPE-SP (2011), são algumas das instituições que definem diferentes designações, como mostrado no Quadro 1. A norma de impermeabilização NBR 9575 (ABNT, 2003) considerava como microfissura a abertura inferior a $0,05 \mathrm{~mm}$; as aberturas com até $0,5 \mathrm{~mm}$ eram chamadas de fissuras e, por fim, as maiores de $0,5 \mathrm{~mm}$ e menores de $1,0 \mathrm{~mm}$, trincas. Em 2010, essa norma foi revista e deixou de classificar a amplitude das aberturas, referindo-se apenas a fissuras como "aberturas variáveis" (ABNT, 2010). A norma NBR 13755 (ABNT, 2017) não estabelece o limite de amplitude para fissura, mas define que trinca são fissuras com abertura igual ou superior a $0,6 \mathrm{~mm}$. Esta norma não cita os termos rachadura, fenda ou brecha, e nem define com clareza os conceitos de fissura e trinca. Outra classificação, destacada pelo CSTB (Centre Scientifique et Technique du Bâtiment), citada por Gaspar, Flores-Colen, Brito (2007), como mostrada no Quadro 1, aborda questões de durabilidade da fachada, essencialmente devida à perda de estanqueidade dos revestimentos.

Quadro 1. Nomenclaturas das aberturas de acordo com diferentes fontes.

\begin{tabular}{|c|c|c|c|c|c|}
\hline \multirow{2}{*}{ Nomenclatura } & IBAPE-MG & IBAPE-SP & NBR 9575 & NBR 13755 & CSTB \\
\cline { 2 - 5 } & \multicolumn{5}{|c|}{ Abertura (mm) } \\
\hline Microfissura & - & - & $<0,05$ & - & Até 0,2 \\
\hline Fissura & Até 0,5 & Até 0,5 & Até 0,5 & $>0,6$ & 0,2 a 2 \\
\hline Trinca & 0,5 a 1,5 & 0,5 a 1,0 & 0,5 a 1,0 & & - \\
\hline Rachadura & 1,5 a 5,0 & $>1,0$ & - & - & - \\
\hline Fenda & 5,0 a 10 & - & - & - & $>2$ \\
\hline Brecha & $>10$ & - & - & - & - \\
\hline
\end{tabular}

Fonte: Elaboração das autoras, a partir de IBAPE-MG (2014), IBAPE-SP (2011), ABNT (2003, 2010, 2017), Gaspar, Flores-Colen, Brito (2007).

Diante desse leque de opções de classificação e embasado na diversa revisão de literatura sobre o tema, neste texto, será utilizado o seguinte critério: microfissura até $0,5 \mathrm{~mm}$; fissura, de $0,5 \mathrm{~mm}$ a $1,5 \mathrm{~mm}$ e trincas, valores de abertura superiores a $1,5 \mathrm{~mm}$. Ressalta-se que as classificações das 
aberturas em diferentes nomenclaturas são uma forma de apresentar suas amplitudes, mas não definem o grau de risco dessa manifestação patológica.

Este tipo de anomalia pode ter diferentes causas. No que tange à constituição dos revestimentos, podem ser listadas: retração (quando tensões de tração elevadas instalam-se no plano de aderência entre revestimento e o suporte ou entre uma camada e sua precedente, pelo fato desta ser mais rígida, restringir a retração, podendo dar origem ao aparecimento de descontinuidades); dilatações e contrações higrotérmicas (quando ocorre falta de continuidade construtiva entre o revestimento e o suporte sobre o qual está aplicado, não só pela deficiência inicial de aderência, mas também pelos diferentes tipos de materiais utilizados, com variáveis coeficientes de dilatação térmica e higrométrica); gelo (a transformação em gelo da água absorvida pela argamassa, com o consequente aumento de volume no interior dos poros, o que gera tensões); deficiente dosagem na execução da argamassa (para resistirem bem às fontes de tensões de tração a que estão sujeitas, as argamassas devem ter retração moderada e módulo de elasticidade reduzido); espessura inadequada do revestimento (Veiga, 1997). Quanto maior a espessura da camada, maior será a resistência à fissuração do revestimento; no entanto, o aumento indefinido da espessura pode gerar o seu descolamento pela ação do seu próprio peso e da maior retração diferencial, quando superado o limite de aderência ao suporte.

Como causas atribuíveis ao suporte, tem-se: fissuração e deslocamento; reações com sais (os sais contidos no suporte sobre o qual está aplicado o revestimento podem ser transportados através da água que percola em seu interior e assim reagir com os componentes deste; ao reagirem, os sais cristalizam e os cristais formados, expandindo-se, provocam a fissuração do revestimento). Ainda podem ser citadas outras causas, tais como: absorção excessiva do suporte, concentração de tensões junto a aberturas e corrosão dos elementos metálicos instalados nas fachadas.

A perda de aderência entre o revestimento e o suporte ao qual foi aplicado ou entre as camadas de reboco pode manifestar-se de três formas distintas: descolamento, abaulamento ou destacamento. O descolamento caracteriza-se pela separação entre o revestimento e seu suporte, podendo ser identificado pelo som oco que se ouve, quando submetido à percussão. $\mathrm{O}$ termo abaulamento consiste na percepção da formação de convexidades na superfície do revestimento, enquanto o destacamento se refere à separação definitiva do seu suporte. Todas estas manifestações têm como principal causa a presença de água no suporte, que pode levar à cristalização de sais expansivos existentes no próprio material. No destacamento, a dilatação decorrente da expansão dos sais produz um impulso perpendicular ao plano de interface entre camadas, podendo superar a capacidade de aderência.

De forma geral, a perda de aderência pode ter ainda outras causas prováveis, tais como: movimentos diferenciais entre o suporte e as camadas de revestimento; defeitos de execução (quantidade excedente de água de amassamento; falta de umedecimento do suporte; inadequada limpeza da superfície a ser revestida; ausência de rugosidade do suporte; espessura excessiva do revestimento; composição pouco adequada da argamassa); dilatações e contrações térmicas (variações dimensionais do reboco); elevada impermeabilidade à água do suporte e insuficiente permeabilidade ao vapor de água do revestimento.

Outra manifestação patológica típica em fachadas corresponde ao fenômeno denominado eflorescência, caracterizada pela formação de substância de aparência cristalina ou filamentosa, geralmente de cor esbranquiçada, e que aflora à superfície alterando o aspecto visual do revestimento. Para que se produza o fenômeno da eflorescência, é necessária a existência simultânea de três fatores: presença de umidade, existência de sais solúveis nos materiais constituintes do revestimento ou do suporte e pressão hidrostática para propiciar a migração da solução para a superfície. Quando a cristalização dos sais ocorre antes destes chegarem à superfície, em alguma cavidade do próprio material, o dano designa-se por criptoflorescência, que tem certo poder destruidor e pode afetar, em alguns casos, a vida útil do material (Carrió, 2000). 
Para o desencadeamento do processo patológico importa ainda a porosidade do revestimento, bem como seu coeficiente de absorção, já que estas características facilitam, para mais ou para menos, a quantidade de água que atravessa o material, que faz com que acelere ou atrase o aparecimento da anomalia. Fatores como variação da temperatura, evaporação da água e diminuição da umidade relativa do ambiente podem conduzir ao aumento na concentração da solução salina e, consequentemente, favorecer a cristalização dos sais.

Os danos mais significativos ocorrem quando os cristais são formados nos poros e nos vasos capilares dos materiais, já que a cristalização se dá, em geral, com dilatação, implicando em um impulso sobre a camada de material que cobre a cavidade, e que tende, assim, a se desagregar.

A perda de coesão ou desagregação consiste na desintegração dos componentes do revestimento, seguida por considerável perda das partículas que o compõem, convertendo-o em um material frágil e suscetível à degradação. As causas mais prováveis para este tipo de anomalia são: umidade seguida de cristalização de sais; reboco fraco, sem dureza superficial; ação de microrganismos e organismos; reação química entre os materiais que constituem os revestimentos e os compostos naturais ou artificiais (poluição) contidos na atmosfera.

No que tange à biodeterioração, consideram-se todos aqueles organismos ou microrganismos vivos, animais ou vegetais (algas, musgos, líquens, fungos, plantas diversas e animais de porte), que de alguma forma deterioram as superfícies dos revestimentos, quer por sua simples presença, quer pelo ataque destes ou dos produtos químicos que expelem. Em geral, estes são capazes de atacar e degradar os materiais. Às vezes, apenas a presença física de células microbianas é suficiente para causar danos, mas em geral a deterioração é causada pela excreção de produtos do metabolismo.

Com origem variada, provenientes do solo ou do ar e transportados por meio da ação do vento, de insetos e de aves, entre outros, os microrganismos depositam-se nas superfícies dos revestimentos, bem como nas descontinuidades e vazios aí existentes, e multiplicam-se conforme seu metabolismo, a disponibilidade dos nutrientes e ainda em função das condições climáticas da região onde está inserido o edifício. A presença prolongada destes nas superfícies das fachadas pode constituir mecanismo de fixação de umidade e barreira para a sua evaporação. Em algumas situações, o biofilme colorido originado por determinadas algas, cianobactérias e líquens, em especial, pode ser visto como parte da sujidade do edifício, integrando-se à imagem coletiva do próprio monumento (Magalhães, 2013).

As condições climáticas do entorno do edifício (umidade relativa do ar, temperatura, vento, entre outros aspectos), a presença de oxigênio e a falta de ventilação são algumas condicionantes extrínsecas que favorecem a fixação e a proliferação dos microrganismos sobre as superfícies dos revestimentos de fachadas, contribuindo, significativamente, para sua deterioração. Condicionantes intrínsecas aos revestimentos como a presença prolongada de umidade, o $\mathrm{pH}$ e a porosidade elevada podem também favorecer o seu crescimento e propagação.

A degradação causada pelas plantas sobre o revestimento decorre do crescimento das suas raízes e da excreção de ácidos que provoca a dissolução dos constituintes das argamassas (silicatos e carbonatos). Locais úmidos como, por exemplo, fendas e fissuras ou revestimentos ligeiramente destacados e ricos em matéria orgânica constituem ambientes que propiciam a fixação e germinação dessas plantas.

A ação dos animais de pequeno porte (aves, insetos) ocorre diretamente através da acumulação de seus excrementos, seguida de ataque químico (pelas fezes fortemente ácidas) dos materiais constituintes do revestimento, e indiretamente, por conterem compostos de nitrogênio (amônia) e fósforo que servem de substrato para o desenvolvimento de outros organismos.

A erosão compreende, de forma geral, a destruição ou o desgaste do revestimento, implicando perda de material, ou unicamente a alteração da superfície (do seu aspecto ou textura exterior). Estes fenômenos resultam da ação erosiva de agentes mecânicos, físicos ou químicos. As causas 
mais prováveis para este tipo de anomalia são: umidade, esforços mecânicos de natureza diversa, ações físicas dos agentes atmosféricos e perda de coesão.

Por fim, a sujidade é caracterizada pelo recobrimento dos revestimentos com poeiras, fuligem e outras partículas poluentes existentes em suspensão na atmosfera. As causas mais prováveis deste tipo de anomalia podem ser: escorrimento da água de chuva, ação do vento e rugosidade superficial do reboco.

Muitos desses danos aqui expostos são observados nas fachadas de edifícios do Centro Histórico de Salvador, área que abriga um dos maiores patrimônios histórico, artístico e cultural da América Latina e que foi tombada pelo Instituto do Patrimônio Histórico e Artístico Nacional (IPHAN) em 1984.

\section{DANOS EM FACHADAS DE EDIFÍCIOS TRADICIONAIS NO CHS}

Esta sessão aborda uma sistematização dos principais danos encontrados nos revestimentos de fachada de edifícios tradicionais, situados no Centro Histórico de Salvador, construídos provavelmente com paredes de alvenaria de pedra e tijolo, aglomerada com argamassa de cal e originalmente revestidas por reboco deste mesmo material.

Para o desenvolvimento do presente trabalho, foram selecionadas três edificações de acordo com os seguintes critérios: uso residencial; localização em área tombada do CHS; revestimento de fachada em argamassa, apresentando sinais de degradação.

Os casarões localizam-se ao lado da Igreja e Convento de Nossa Senhora do Carmo e constituem importante conjunto de valor histórico, artístico e cultural para a cidade. O tecido urbano nessa área se desenvolveu mais intensamente a partir de meados do século XVIII, data provável da construção dos casarões que passaram por intervenções nas suas fachadas no século XIX.

A Figura 1 mostra a localização das edificações de estudo na área tombada, a Figura 2 ilustra os casarões inseridos na ambiência da rua do Carmo, no Centro Histórico e a proximidade com a Igreja, e a Figura 3, as respectivas imagens das fachadas principais e o estado geral destas.

As fachadas dos casarões possuem elementos arquitetônicos distintos, representando soluções típicas de épocas diferenciadas, conforme ilustra a Figura 3. O edifício $\mathrm{n}^{\mathrm{o}} 41$, diferentemente dos outros dois, possui marcação das aberturas das portas em cantaria. Os casarões $n^{\circ} 43$ e $n^{\circ} 45$ apresentam, no embasamento, aberturas com ornamentos decorativos em argamassa para ventilação do porão. As espessuras das argamassas são variáveis, decorrentes das diversas intervenções pelas quais as fachadas das edificações passaram ao longo dos anos. No entanto, não foi possível observar a quantidade de camadas e a composição, bem como o tipo da tinta utilizada. Atualmente, essas edificações contam apenas com as fachadas externas e encontram-se classificadas pela Defesa Civil de Salvador - CODESAL (2009) como construções de médio risco ${ }^{3}$. Vale destacar que as aberturas das fachadas foram fechadas com alvenaria para dar maior estabilidade às construções (já que não possuem travamentos internos ${ }^{4}$ ) e para impedir o acesso de pessoas e animais ao interior da edificação, evitando a invasão da propriedade.

\footnotetext{
${ }^{3}$ Deve-se ressaltar que essa classificação é realizada com base na estabilidade e conservação das estruturas dos imóveis, bem como no risco presumido ao morador, transeuntes e vizinhos.

${ }^{4}$ A falta da cobertura e dos pisos/assoalhos internos propicia a perda de vínculos da estrutura e, consequentemente, pode gerar instabilidade.
} 


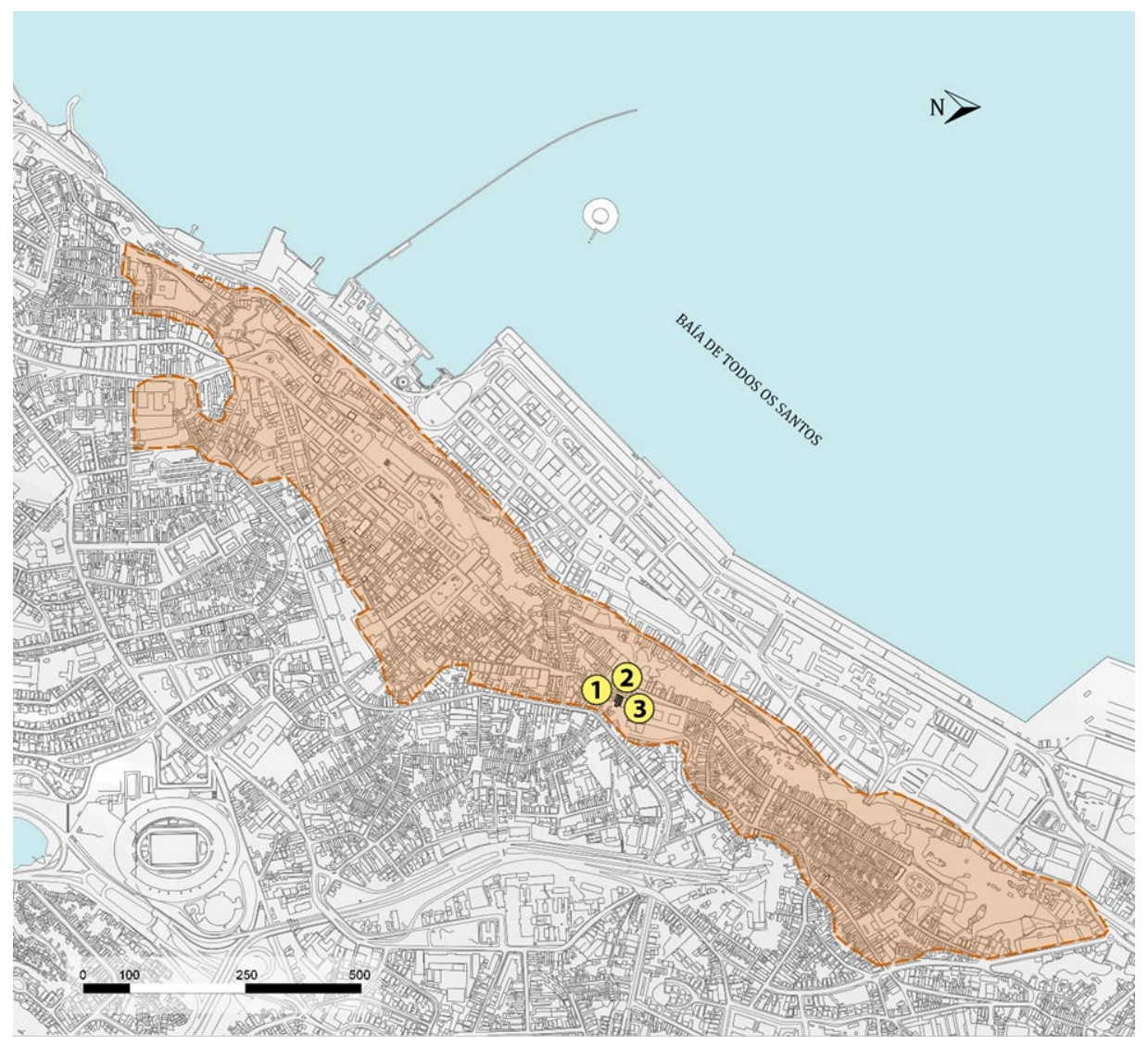

LEGENDA

Delimitação do Centro Histórico de Salvador

Edificações de estudo na Ladeira do Carmo, Santo Antônio

(1) Casarão no 41

(2) Casarão no 43

(3) Casarão no 45

Figura 1. Localização das edificações de estudo.

Fonte: Elaboração das autoras, 2021, a partir de Salvador (1983) e Prefeitura Municipal do Salvador (2017).

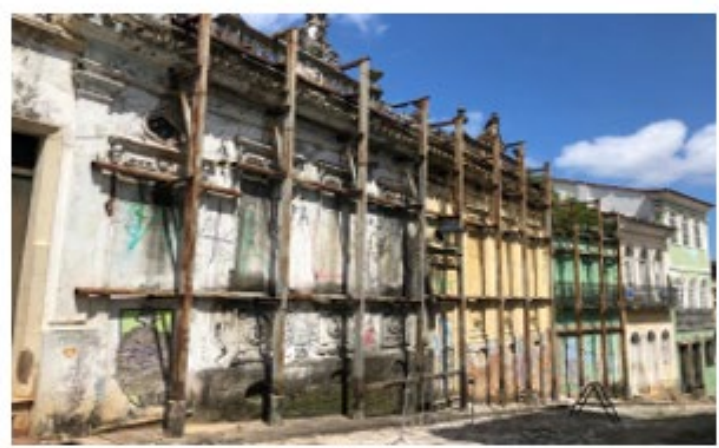

(a)

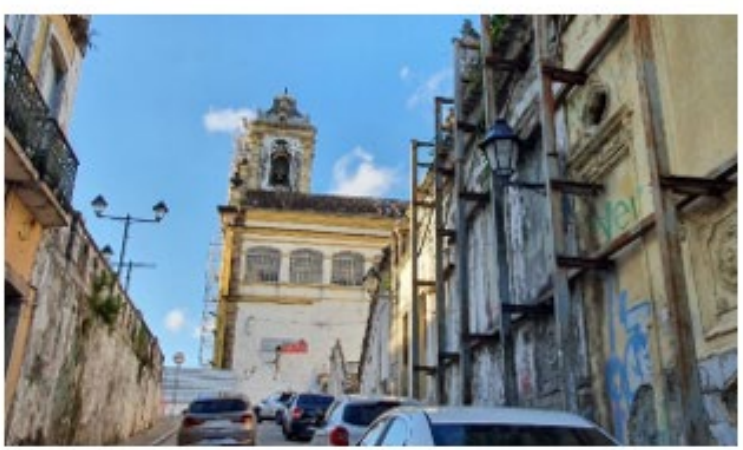

(b)

Figura 2. (a) Edificações de estudo localizadas na Rua do Carmo $n^{\circ} 45, n^{\circ} 43$ e $n^{\circ} 41$ (da esquerda para a direita), no Centro Histórico de Salvador; (b) Casarões de estudo e a Igreja e Convento de Nossa Senhora do Carmo.

Fonte: Acervo das autoras, 2021. 


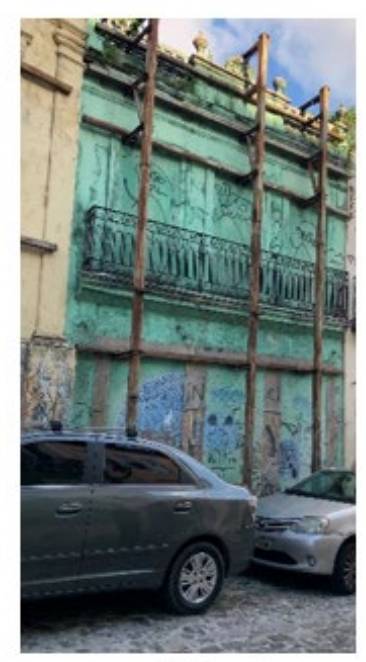

(a)

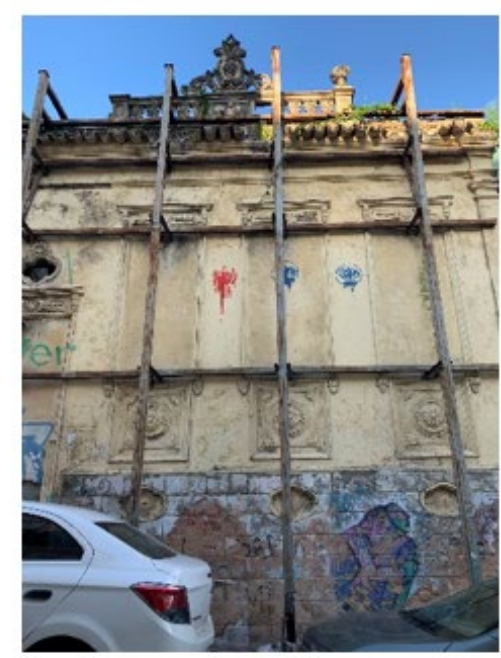

(b)

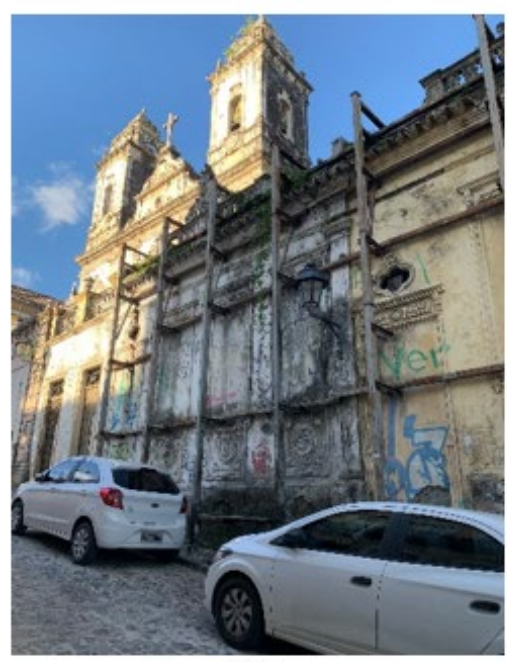

(c)

Figura 3. Fachadas principais dos casarões (a) $n^{\circ} 41$; (b) no 43 ; (c) $n^{\circ} 45$.

Fonte: Acervo das autoras, 2021.

Os referidos fechamentos passaram por intervenções recentes com aplicação de argamassa de cimento, como mostra a Figura 4a. Os paramentos externos possuem escoramentos metálicos que se encontram quase que totalmente degradados, com provável perda de função estrutural (Figura 4b). Esta situação é agravada com o vandalismo e roubo de peças dos escoramentos (Figura 4c).

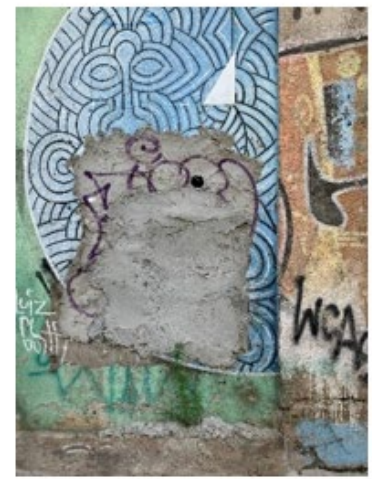

(a)

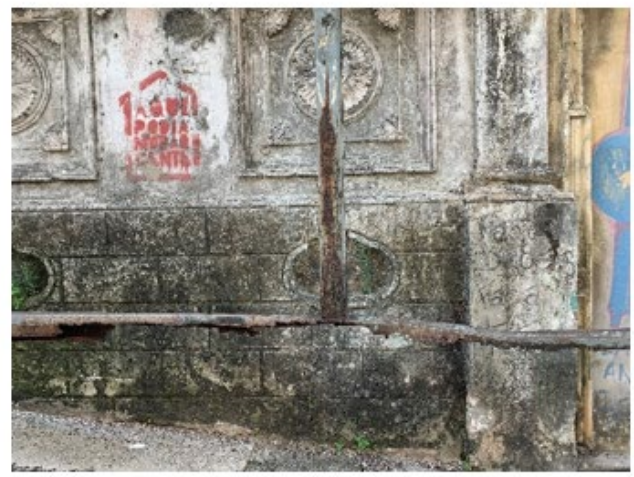

(b)

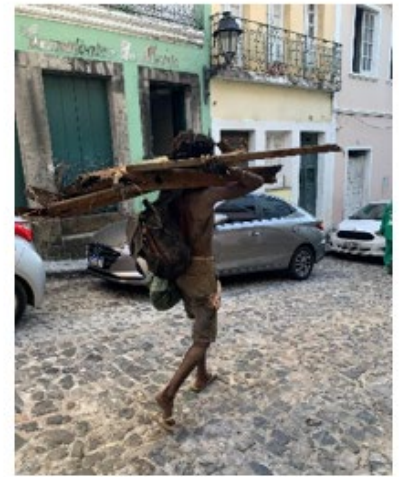

(c)

Figura 4. (a) Fechamento de vão com argamassas de cimento; (b) Escoramento metálico da fachada da edificação $n^{\circ} 45$, apresentando degradação e falta de apoio; (c) Vandalismo. Fonte: Acervo das autoras, 2021.

Para os três casarões de estudo, após observação dos revestimentos de fachadas, foi realizado detalhado diagnóstico das principais anomalias e extraídas conclusões sobre suas prováveis causas. Entre os danos mais comuns, destacam-se: manchas de umidade decorrentes da percolação da água do solo e de infiltração pela cobertura, fissuras e trincas nos materiais; perda de aderência; desagregação; biodeterioração; sujidade; perda de elementos decorativos; perda de camada pictórica; vandalismo; conforme Quadro 2 e Figura $5^{5}$.

\footnotetext{
${ }^{5}$ As imagens da Figura 5 são representativas dos danos identificados nos casarões de estudo. Neste trabalho, devido ao respeito das normas de formatação, foram selecionadas apenas imagens para representar os danos das edificações.
} 
Quadro 2. Descrição dos principais danos e suas prováveis causas, identificados nas fachadas dos casarões no $41, n^{\circ} 43$ e nº 45 da Ladeira do Carmo, Centro Histórico de Salvador.

\begin{tabular}{|c|c|}
\hline Danos/Local & Prováveis Causas \\
\hline $\begin{array}{l}\text { Manchas de umidade } \\
\text { ascendente } \\
\text { / Todos os casarões }\end{array}$ & $\begin{array}{l}\text { Acúmulo de água no solo devido à falta de cobertura e de drenagem } \\
\text { (Figuras } 5 \mathrm{a}, 5 \mathrm{~b}, 5 \mathrm{c} \text { e } 5 \mathrm{~d} \text { ). O microclima no interior das construções } \\
\text { propicia o desenvolvimento de densa vegetação (Figura } 7 \mathrm{e} \text { ), que favorece } \\
\text { a percolação de água pelo paramento. Observa-se que nas edificações } \mathrm{n}^{\circ} \\
43 \text { e } \mathrm{n}^{\circ} 45 \text { as aberturas de ventilação do subsolo encontram-se obstruídas. }\end{array}$ \\
\hline $\begin{array}{l}\text { Manchas de umidade } \\
\text { descendente } \\
\text { / Todos os casarões }\end{array}$ & $\begin{array}{l}\text { Acúmulo de água de chuva na parte superior dos edifícios pela falta de } \\
\text { cobertura e inexistência de sistema de coleta e escoamento de águas } \\
\text { pluviais por meio soluções construtivas (Figuras } 5 \mathrm{f} \text { e } 5 \mathrm{~g} \text { ). }\end{array}$ \\
\hline $\begin{array}{l}\text { Descontinuidades } \\
\text { (fissuras e trincas) } \\
\text { / Casarões } n^{\circ} 41 \text { e } n^{\circ} 43\end{array}$ & $\begin{array}{l}\text { Presença de umidade no interior das paredes das fachadas, (intempéries), } \\
\text { utilização de materiais inadequados (falta de compatibilidade com o } \\
\text { suporte), movimentação das fachadas (Figuras } 5 \text { h e } 5 \mathrm{i} \text { ). }\end{array}$ \\
\hline $\begin{array}{l}\text { Perda de aderência } \\
\text { / Casarões no } 41 \text { e n }{ }^{\circ} 45\end{array}$ & $\begin{array}{l}\text { Presença de umidade, uso de material inadequado (Figura } 5 \mathrm{j} \text { ). Em } \\
\text { revestimentos com base em cal, a ação prolongada da umidade vai } \\
\text { dissolvendo ("lavando") o ligante até o seu total desaparecimento, } \\
\text { favorecendo a perda de coesão e de aderência dos materiais. Observa-se, } \\
\text { no casarão n } \text { n }^{\text {o }} 45 \text {, o destacamento do revestimento da fachada, } \\
\text { provavelmente, por causa da ação das intempéries, de choque mecânico } \\
\text { dada a perda de elementos superiores (Figura } 5 \mathrm{k} \text { ). }\end{array}$ \\
\hline $\begin{array}{l}\text { Desagregação } \\
\text { / Casarão nº } 43\end{array}$ & $\begin{array}{l}\text { Presença de umidade e sais solúveis, falta de proteção (pintura) adequada } \\
\text { (Figura 5c). Os sais, ao cristalizarem, aumentam de volume, destruindo o } \\
\text { interior da estrutura porosa da argamassa. }\end{array}$ \\
\hline $\begin{array}{l}\text { Biodeterioração } \\
\text { / Todos os casarões }\end{array}$ & $\begin{array}{l}\text { Presença de umidade e temperatura propícia para o desenvolvimento de } \\
\text { microrganismos e de vegetação pela deposição de sementes por aves } \\
\text { (Figuras } 51,5 \mathrm{~m}, 5 \mathrm{n} \text { e } 50 \text { ). }\end{array}$ \\
\hline $\begin{array}{l}\text { Sujidade } \\
\text { / Todos os casarões }\end{array}$ & $\begin{array}{l}\text { Presença de umidade e poluição atmosférica que favorecem o depósito de } \\
\text { sujeiras e de poluentes, progressivamente, sobre a superfície das } \\
\text { alvenarias (crosta negra). Ver figura } 5 \mathrm{p} \text {. }\end{array}$ \\
\hline $\begin{array}{l}\text { Perda de elementos } \\
\text { arquitetônicos } \\
\text { / Todos os casarões }\end{array}$ & $\begin{array}{l}\text { Movimentação da fachada pela perda do vínculo gerada pela falta de } \\
\text { cobertura (Figuras } 5 \text { q e 5r). Adiciona-se a este contexto a exposição dessas } \\
\text { peças às intempéries, a presença de umidade e ao decorrente desgaste dos } \\
\text { materiais. }\end{array}$ \\
\hline $\begin{array}{l}\text { Perda de camada } \\
\text { pictórica } \\
\text { / Todos os casarões }\end{array}$ & $\begin{array}{l}\text { Tinta inadequada ao reboco, descolamento em função da água de chuva, } \\
\text { falta de manutenção (Figuras } 5 \text { c e } 5 \mathrm{~s} \text { ). }\end{array}$ \\
\hline $\begin{array}{l}\text { Pixação } \\
\text { / Todos os casarões }\end{array}$ & Vandalismo (Figuras 5t e 5u) \\
\hline
\end{tabular}




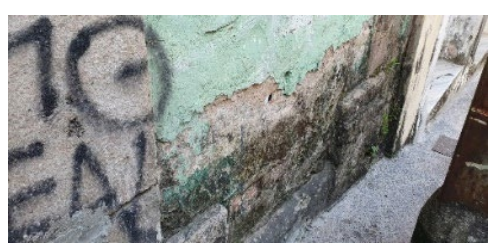

(a)

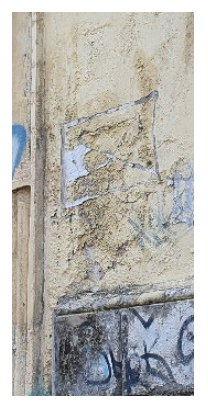

(d)

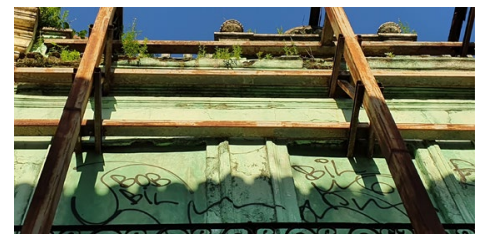

(g)

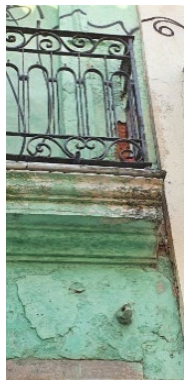

(j)

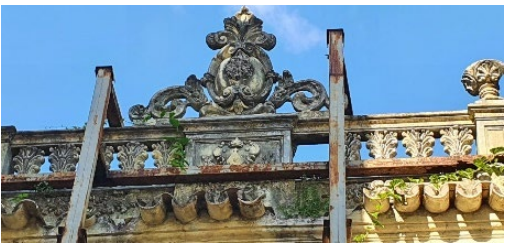

(m)

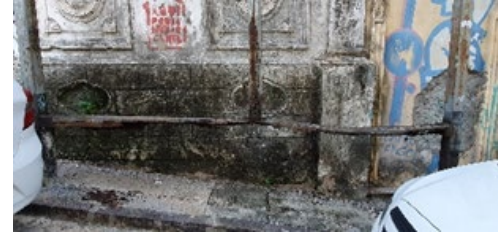

(b)

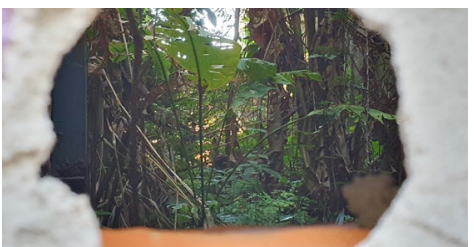

(e)

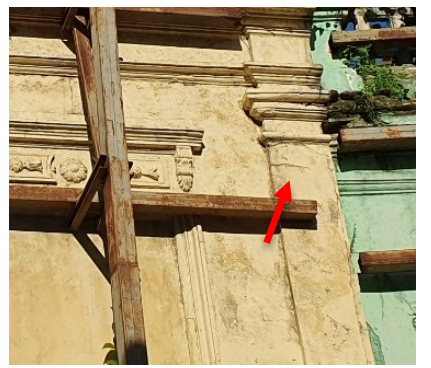

(h)

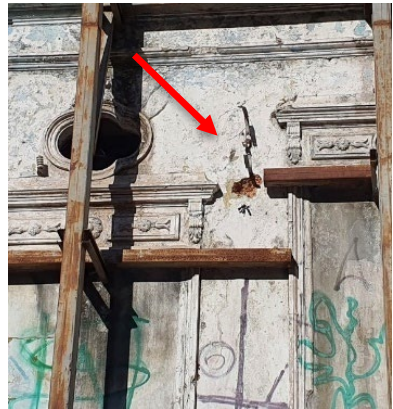

(k)

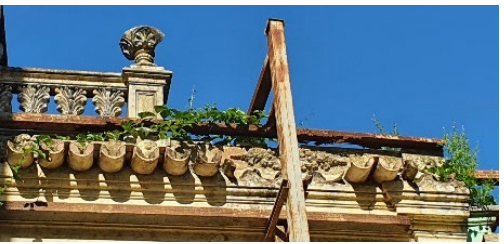

(n)

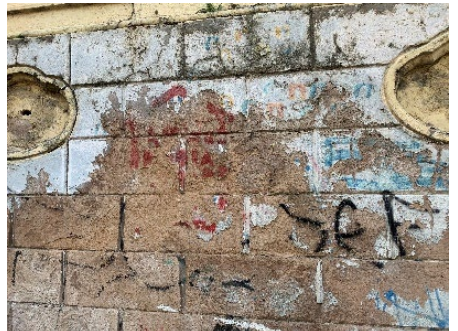

(c)

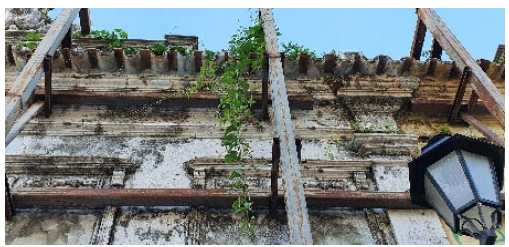

(f)

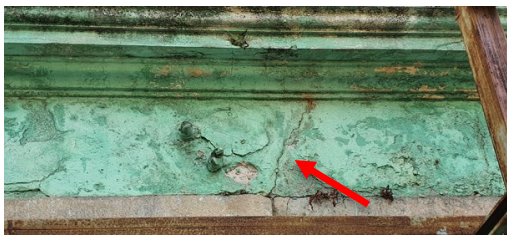

(i)

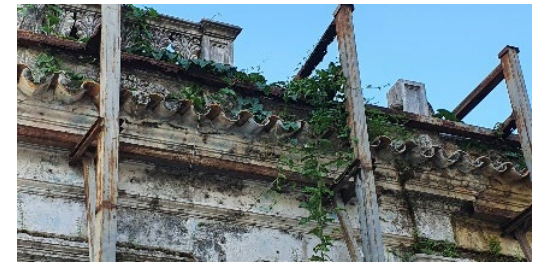

(1)

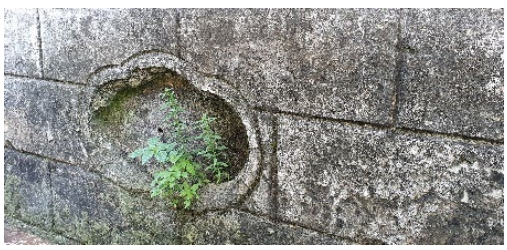

(o)

(continua) 


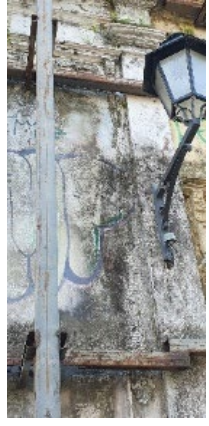

(p)

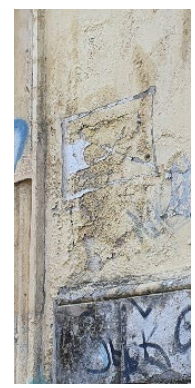

(s)

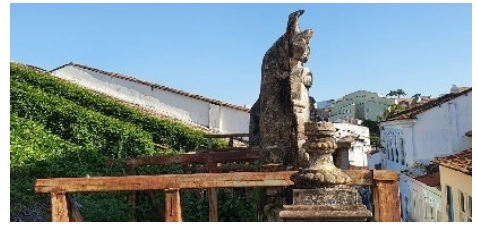

(q)

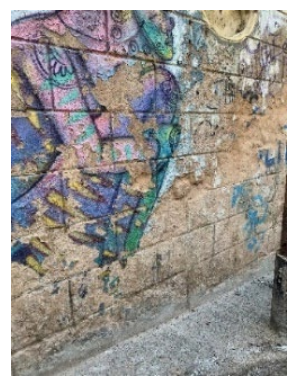

$(\mathrm{t})$

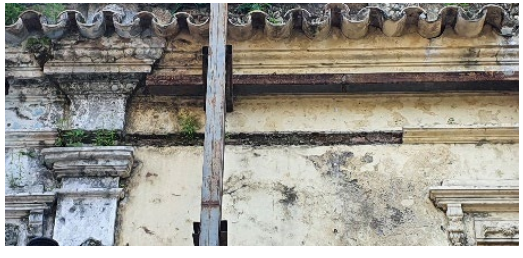

(r)

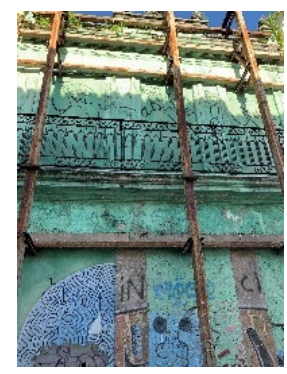

(u)

Figura 5. Detalhes dos danos das fachadas principais dos casarões $n^{\circ} 41, n^{\circ} 43$ e $n^{0} 45$. Fonte: Acervo das autoras, 2021.

De forma geral, os danos encontrados nas estruturas antigas, caracterizadas por sua grande porosidade e espessura, podem estar relacionados ainda aos próprios materiais novos usados nas intervenções e à inadequação das soluções de revestimento adotadas às características do suporte. A presença prolongada de água nas paredes, causa primária dos danos, está na origem das diversas anomalias secundárias e é potencializada pela dificuldade da sua eliminação devido à reduzida capacidade de evaporação da água pelos novos revestimentos em relação aos originais (de cal aérea, muito porosos e permeáveis).

\section{CONSIDERAÇÕES FINAIS}

A atuação conjunta de vários fatores leva à degradação dos revestimentos. Além das ações às quais os edifícios estão sujeitos nas condições normais de utilização (temperatura, vento, chuva, umidade relativa do ar, umidade que percola no interior das paredes), fatores como vandalismo, abandono e falta de manutenção preventiva (reparações pontuas e pintura periódica, quando necessárias) contribuem decisivamente para a aceleração natural da degradação do edifício.

De forma geral, pôde-se constatar que os danos detectados nos casarões da Ladeira do Carmo, no Centro Histórico de Salvador, decorrem significativamente do seu estado de abandono por longo período, da falta da proteção da cobertura, da ação das intempéries sobre os materiais, bem como da ação humana.

De forma geral, os revestimentos (rebocos e pinturas) não devem reter água que se infiltra por meio das fundações, por ascensão capilar, ou por meio das coberturas; nem contribuir para introduzir sais no suporte; e nem ter, em sua constituição, baixos teores de sais. Devem, ainda, possuir características mecânicas semelhantes aos antigos revestimentos e não superiores às das alvenarias, 
para não terem grandes deformações diferenciais que produzam perdas de aderência e nem transmitirem tensões elevadas à alvenaria.

As intervenções nas edificações de interesse histórico devem seguir princípios orientadores que garantam a manutenção do seu significado cultural e da sua salvaguarda para o futuro, especialmente no que tange à manutenção da autenticidade do edifício e compatibilidade entre os novos materiais e os antigos. Quaisquer medidas de conservação e restauro só devem ser tomadas após eliminação das causas que provocam as anomalias. Estas passam, principalmente, pela correção dos locais de infiltração, por meio da reparação das coberturas e da execução de sistemas de drenagem, e pelo controle da entrada de água por outras vias (ascensão por capilaridade); não menos importante, pela determinação do uso da edificação.

Cabe mencionar que ao se tratar de bens tombados, é o proprietário da edificação responsável pela manutenção. Pela lei, é obrigado a conservá-lo e, caso não apresente condições financeiras, deve entregá-lo ao poder público para que seja preservado, já que é proibida sua demolição. Ressalta-se que no contexto atual, os órgãos responsáveis pela gestão do patrimônio histórico ou não possuem ou dispõem de escassos recursos para abarcar com todo esse legado.

Por fim, a importância deste trabalho está não somente no levantamento e sistematização dos danos mais comuns encontrados em revestimentos de fachadas de edificações tradicionais, para auxiliar na elaboração do projeto de intervenção, mas também para alertar a comunidade e as autoridades para a tomada de medidas criteriosas que visem a preservação do patrimônio edificado.

\section{REFERÊNCIAS}

Associação Brasileira de Normas Técnicas, ABNT. (2003). NBR 9575: Impermeabilização e Projeto. Rio de Janeiro.

Associação Brasileira de Normas Técnicas, ABNT. (2010). NBR 9575: Impermeabilização e Projeto. Rio de Janeiro.

Associação Brasileira de Normas Técnicas, ABNT. (2017). NBR 13755: Revestimentos cerâmicos e paredes externas com utilização de argamassa de fachadas colante. Rio de Janeiro.

Brasil. Ministério da Cultura. (2005), "Manual de elaboração de projetos de preservação do patrimônio cultural” Programa Monumenta, cadernos técnicos 1. Brasília: Ministério da Cultura, Instituto do Programa Monumenta.

Carrio, J. M. (2000), “Patología de cerramientos y acabados arquitectónicos”. Editorial Munilla Lería, Madrid, España.

Defesa Civil de Salvador, CODESAL (2009), “Casarões - Relatório Técnico”. Prefeitura Municipal de Salvador, Salvador. https: www.defesacivil.salvador.ba.gov.br. Acesso em: 22 ago. 2020.

Gaspar, P., Flores-Colen, I., Brito, J. (2007), Técnicas de diagnóstico e classificação de fissuração em fachadas rebocadas. Revista Internacional Construlink. 5. 26-34. https://www.researchgate.net/publication/280098489_Tecnicas_de_Diagnostico_e_Classificacao de_Fissuracao_em_Fachadas_Rebocadas. Acesso em 04 de maio 2021.

Henriques, F. (2001), “Humidade em paredes”. LNEC, Lisboa, Portugal. 
Instituto Brasileiro de Avaliações e Perícias de Engenharia de Minas Gerais, IBAPE-SP. (2011). Norma de Inspeção Predial. São Paulo. https://ibape-sp.org.br/adm/upload/uploads/1602690838NORMA-DE-INSPECAO-PREDIAL-2011.pdf. Acesso em 01 jun. 2021.

Instituto Brasileiro de Avaliações e Perícias de Engenharia de Minas Gerais, IBAPE-MG. (2014). Norma de Vistoria Cautelar. Belo Horizonte. https://www.ibapemg.com.br/2018/wpcontent/uploads/ibape-mg-norma-cautelar.pdf. Acesso em 01 jun. 2021.

Magalhães, A. (2013), “Degradação de revestimentos de paredes de edifícios antigos: metodologia de diagnóstico", Dissertação de mestrado, Universidade Federal da Bahia.

Prefeitura Municipal do Salvador. (2017), "Base Cartográfica Digital Cadastral de Referência". Prefeitura Municipal do Salvador, Salvador. http://mapeamento.salvador.ba.gov.br/geo/desktop/\#on=layer/default;scalebar_meters/scalebar_ m;orto2016/Ortoimagem_Salvador_2016_2017\&loc=76.43702828517625;-42778080;-1445884. Acesso em: 01 ago. 2020 .

Salvador. (1983). Lei $n^{\circ} 3.289$, de 21 de setembro de 1983. Altera e dá nova redação a dispositivos da Lei $n^{\circ}$ 2.403, de 23 de agosto de 1972, e dá outras providências. Câmara Municipal, Salvador. https://www.jusbrasil.com.br/topicos/13540356/artigo-108-da-lei-n-3289-de-21-de-setembro-de1983-do-municipio-de-salvador. Acesso em: 09 set. 2020.

Sousa, V., Pereira, F.; Brito, J. (2005), Rebocos Tradicionais: Principais Causas de Degradação. Engenharia Civil. Universidade do Minho. 23: http://www.civil.uminho.pt/revista/artigos/Num23/n_23 pag_05-18.pdf. Acesso em 23 de fev. 2021.

Veiga, M. (1997), "Comportamento de argamassas de revestimento de paredes. Contribuição para o estudo da sua resistência à fendilhação", Tese de doutoramento, Faculdade de Engenharia da Universidade do Porto.

Veiga, R.; Tavares, M., (2002). “Características de paredes antigas. Requisitos dos revestimentos por pintura" in: Actas do Encontro A indústria das tintas no início do século XXI, APTETI, Lisboa. http://conservarcal.lnec.pt/pdfs/RVMT_APTETI.pdf. Acesso em 23 de fev. 2021.

Villanueva, L. (1998), "Patología de guarnecidos y revocos, in: Patología y técnicas de intervención. Fachadas y cubiertas. Tomo 4. Editorial Munilla Lería, Madrid, España. 